\title{
Exploration and Analysis of the Relationship between the Real Estate and the Third Industry in the Coal Resource Based Cities
}

\author{
Ran Zhang \\ Xi'an University Of Architecture and Technology,Xi'an 710000,China \\ $174793242 \cdot q q c o m$
}

Keywords: coal resource-based cities, the real estate industry, related industries, the tertiary industry.

\begin{abstract}
The coal resource based city is a city type which to local coal, mineral and other natural resources exploitation, processing as the leading industry.In recent years, due to the non-renewable natural resources, resource price volatility and other factors of the interaction, making the real estate market is very fragile. Taking Yulin Shaanxi as an example, this paper studies the problem of the real estate industry of resource based cities through statistical data, and uses the input-output method to calculate the direct consumption coefficient, finds that the third industry and urban real estate industry have the strongest correlation. Finally, through the prediction of the development model, it is found that to accelerate the development of the third industry, can overcome the negative impact of the lack of natural resources, and make the resource based city full of second life.
\end{abstract}

\section{Introduction}

Resource based cities have their own real estate market, which is different from the general cities because of their unique advantages, which are closely related to the real estate industry and the city reserve. By taking Yulin city of Shaanxi as an example, because of the ground floor of the rich coal, oil, natural gas and other resources here as Cuntucunjin City, mineral resources, the potential value of more than 46 trillion yuan, making Yulin is known as "China's Kuwait". ${ }^{[1]}$ but in the last two years, Yulin's housing prices fell sharply, real estate investment is unusually bleak. As a city of coal, because of its nonrenewable resources, high volatility of resources and large population mobility and other reasons, leading to the development of the real estate industry in Yulin has a distinctive feature, the impact of various phenomena for the local real estate market need to be further research. Problems have emerged, how to when the resource is no longer an advantage of a city, to find other alternative industries, the resource type city not because of its natural resource shortages or price fluctuations and lonely, won't let the real estate market Nixonian levels, is the research objective.

\section{Problems in the real estate industry in resource based cities}

From Xi'an city and Yulin city in recent years, the GDP change curve can be seen, Xi'an city in recent years, economic growth is relatively stable, and the Yulin economic growth rate has changed, especially in the last three years, due to the continued decline in resource prices, resulting in a sharp reduction in income and investment resources, so as to make rapid economic growth. The economic development trend of Yulin city is in line with the existing problems in the development stage of the resources based cities in the world. Yulin city in 2014 the second industry accounted for 68.3\% of GDP, while the five pillar industries associated with the $89 \%$ industry, and therefore the entire city of mining based resources industry is quite high dependence. This is the main reason for the sharp fluctuations in the entire city GDP. As the economic development of Yulin is highly dependent on the mining industry, other industries of the whole city are closely related with the city's mining industry. ${ }^{[2]}$

Yulin's economic growth slowed down to the region's real estate market as a result of the price volatility of mineral resources, resulting in the city's commercial housing sales fell sharply in 2014, a decline of more than 30\%. In addition to the beginning of 2012, Yulin commercial housing price fell sharply, to the end of 2014 has not been restored to the average level in 2011. Yulin commercial 
housing price decline in time and resource prices fell by the time is completely coincident, the developers in the amount of price change, the entire real estate market, the number of new projects and the completion of a substantial reduction in the city's real estate market is still sluggish, which from 2014 sales fell sharply.

Can be seen from the above data, such as Yulin, such as domestic coal based mineral resources in the city in the resources price fluctuations, the real estate market is very poor anti risk ability. The whole city real estate market with the performance of the resources industry, the performance of the phenomenon is very significant volatility, the local people's life has brought a lot of risk, there are reports that nearly two years due to the resource industry downturn, Yulin region has 200000 surplus labor migration to other cities. In view of the above problems, this paper presents a mathematical model to find a best alternative industries, can significantly improve the anti risk ability of resource type city housing estate industry, and which is capable of stabilizing the subsequent development of the whole city.

\section{Construction of the real estate industry association system}

\subsection{To define the related concepts of industrial relevancy}

Industrial linkage is the intrinsic link between the mutual relation and the mutual existence condition of the product supply and demand. Real estate industry as a new growth point of our national economy, the important position in the national economy, is not only the supply of many economic factors, but also by many industries. ${ }^{[3]}$ Article mainly for the resource-based cities in Yulin as an example of empirical research, when the peak period of its resources, the real estate market is bound to be hit, the need to extend the industrial chain or other industries to ease the pressure. And other industries of choice, it is required by the quantitative calculation of the real estate industry and other industries to evaluate the degree of relevance.

The relationship between the quantitative industry can be used directly related index, the direct relationship between the supply and demand, and the relationship between the real estate industry and the direct consumption coefficient, the greater the consumption coefficient, the more closely related to the real estate industry. The direct consumption coefficient, also known as the input coefficient, denoted as AIJ, refers to the number of products or services of the product or service in the product department (e.g.I) in the production and management process of a certain product department (e.g.J). The calculation method is based on the input output table data, using the total investment $(\mathrm{Xj})$ of the $\mathrm{j}$ product department to remove the number of products or services in the Department of production and management of the Department of I or number of services Xij. ${ }^{[4]}$

Its calculation formula is: $a i j=x i j / x j \quad(i, j=1,2, \ldots, n)$.

When aij's numerical value is large, indicates that the relationship between the $\mathrm{j}$ industry and the $\mathrm{i}$ industry is closely related;

When aij's numerical value is small, indicates that the relationship between the $\mathrm{j}$ industry and the $\mathrm{i}$ industry is estranged.

When aij's numerical value is 0 , there is no direct relationship between production and consumption in the $\mathrm{j}$ industry and the $\mathrm{i}$ industry.

\subsection{Empirical calculation of the positive correlation between real estate and related industries}

By calculating in 2007, Shaanxi Province, $42 * 42$ and $200242 * 42$ departments of real estate direct consumption coefficient bit time table, and in 2002 in Shaanxi Province 142*142 with 2002's $122 * 122$ sector real estate direct consumption digital time table, analysis of the real estate industry and its existence prior to the correlation industry type of, to find when the resource type city coal resources into recession, the other can be up to replace the role of industry.

Though Table1.1 2007 province 142 x 142 sector real estate industry direct consumption of digital times table in Shaanxi, In the real estate related industries in 60, closely related to 16 (greater than 142 of the real estate industry related to the average value of the direct consumption coefficient), the real estate industry for this kind of industry dependence. One of the 12 industries for the type of industry $($ marked $*)$; after calculation, and the real estate industry has a strong correlation with the direct 
consumption coefficient of 16 (0.3001525) of the total number of three (Chart), 12 of the third industry direct consumption coefficient is 0.2824869 , third 12 industry accounted for 16 of the proportion of real estate companies with 0.9411445.Comparison between 2002 and 2007, 142 (122) in Shaanxi province and the 42 sector of the real estate industry direct consumption coefficient and the proportion of the third industry has been greatly improved by the 122 sector in 20020.4396900 to 0.9411445 in the 142 sector in 2002; by 20070.4719054 to 42 in 200742 departments of 0.9167895 .

From the table we can see that most closely related with the real estate industry is the third industry type, and not the resources industry, and with time the tertiary industry the pulling effect of the real estate industry has become increasingly obvious, indicating that the resource type city real estate industry through the development of the third industry to obtain new vitality, the development of the third industry can in great extent save and revitalize resource type city's local real estate industry. Gradually abandon reliance on coal resources, will play a role in promoting the main industry gradually from the traditional resource production, resource processing industries, manufacturing, etc. heavy industry to service industry, the tertiary industry change is resource type city future development the only way of the real estate.

Table1.1 2007 province 142 x 142 sector real estate industry direct consumption of digital times table in Shaanxi

\begin{tabular}{|c|c|c|c|c|}
\hline Directly Related Industry Name & Code & $\begin{array}{c}\text { DirectconSumption } \\
\text { Coefficient }\end{array}$ & Precedence & $\begin{array}{c}\text { The Tertiary } \\
\text { Industry }\end{array}$ \\
\hline Business services & 74124 & 0.115328 & 1 & $*$ \\
\hline Banking & 68115 & 0.105286 & 2 & $*$ \\
\hline Catering & 67114 & 0.014670 & 3 & * \\
\hline Leasing industry & 73123 & 0.010523 & 4 & * \\
\hline $\begin{array}{l}\text { Electricity, heat production and } \\
\text { supply industry }\end{array}$ & 44092 & 0.006809 & 5 & \\
\hline Railway transportation industry & 51099 & 0.005794 & 6 & $*$ \\
\hline Metal products industry & 34063 & 0.005719 & 7 & \\
\hline Entertainment & 92143 & 0.005459 & 8 & $*$ \\
\hline Lodging industry & 66113 & 0.005336 & 9 & $*$ \\
\hline $\begin{array}{l}\text { Telecommunications and other } \\
\text { information transmission } \\
\text { services }\end{array}$ & 60108 & 0.004902 & 10 & * \\
\hline Property management & 72120 & 0.004878 & 11 & * \\
\hline Road transport industry & 52100 & 0.003664 & 12 & * \\
\hline $\begin{array}{l}\text { Handicraftsother and } \\
\text { manufacturing }\end{array}$ & 42090 & 0.003541 & 13 & $*$ \\
\hline Air transport industry & 55103 & 0.003107 & 14 & * \\
\hline $\begin{array}{l}\text { Special chemical products } \\
\text { manufacturing industry }\end{array}$ & 26044 & 0.002785 & 15 & \\
\hline $\begin{array}{l}\text { Water production and supply } \\
\text { industry }\end{array}$ & 46094 & 0.002352 & 16 & \\
\hline $\begin{array}{c}\text { Total direct consumption } \\
\text { coefficient }\end{array}$ & & 0.3001525 & & \\
\hline $\begin{array}{l}\text { The tertiary industry direct } \\
\text { consumption coefficient total }\end{array}$ & & 0.2824869 & & \\
\hline $\begin{array}{c}\text { The tertiary industry direct } \\
\text { consumption coefficient total / } \\
\text { direct consumption coefficient } \\
\text { total }\end{array}$ & & 0.9411445 & & \\
\hline
\end{tabular}

Source: 2007 Shaanxi input output table 142

\section{Forecast of the relationship between the real estate industry and the development of the tertiary industry in the coal resource based cities}

From the increase of mineral resources in Yulin city and the third industry production value with time variation curve can be seen, in Yulin City, the total value of the third industry relative to the 
mining industry is relatively small. In order to further explain the status of mining industry and the third industry in Yulin City, we will transform the economy into the economic weight, the proportion of Yulin mineral mining and third industries accounted for GDP with time. It can be seen that the proportion of mining industry in Yulin is about $60 \%$, some years even close to $70 \%$, while the proportion of third industries accounted for GDP. So the third industry in Yulin area has a lot of room for development.

The forecast model of this section assumes that the original industry including the mining industry is the same in the past seven years, except for the third industries in Yulin, while the third industry accounts for $25 \%, 60 \%$ and $40 \%$, and the $42 \times 42$ sector of the real estate industry in Shaanxi Province in 2007. When the proportion of the third industry in Yulin has brought the whole city total GDP increase, while Yulin's real estate sales will increase significantly. When the third industry accounted for $60 \%$, the sales of commercial housing rose almost three times. This shows that if the third industry in Yulin is developed, then the real estate industry in Yulin there is a great potential. In fact, the current Yulin City, although the per capita GDP reached 89005 yuan, in Shaanxi and the country are at the forefront, but the agricultural population still has $46.14 \%$, while the wealth is concentrated in the hands of a few people, the lack of middle class support, the development of the third industry can absorb a large number of agricultural population, the middle class, in the process of economic growth, while real estate market capacity and sales will be significantly improved.

Secondly, when the third industry development and expansion of the resource-based cities in real estate sales with the resources industry fluctuations in the amplitude of a significant drop. Especially when the proportion of third industries in Yulin reached 60\% (the average level of our country), the amplitude of sales in 2014 from the original -33\%, down to -7\%, which is consistent with the national commercial housing sales. Therefore, the development of the third industry to the coal based resource based cities not only expand the real estate market capacity, improve the sales of commercial housing, while in the resource price volatility and resource depletion period also played a role in stabilizer. For the stability of the local people's living standards, the successful transformation of the resource-based cities has a very significant role.

\section{Summary}

Through statistical analysis of the typical coal resource cities in Yulin, the paper analyzes the problems of Yulin real estate industry, and the main reason is that the economic structure is too simple, and the mining industry is easy to be influenced by mineral price fluctuation, resource depletion and other factors. Finally, it is found that the development of the tertiary industry can overcome the adverse effects of natural resources, such as the large fluctuations of natural resources.

The study found that not only expanded the capacity of the real estate market, but also increased the sales of commercial housing, and brought the second life to the local real estate industry. Meanwhile, it has played a role of "stabilizer" in the resource price fluctuation and resource depletion. For the stability of the local people's living standards, the successful transformation of the resource-based cities has a very significant role.

\section{Reference}

[1] Zhao Feng, Huang Jie. Yulin: the expansion of the real estate [J]. great western development.2011, (07): 76-78.

[2] Zhang Hongli, the means and the performance of the real estate market in China -- Based on the perspective of industry healthy development [D]. Xi'an University Of Architecture And Technology.2011.4

[3] Lv Chenzhong, Qin Jie. Empirical test of the relationship between the real estate industry fluctuations and the development of the national economy [J].2013. (10): 125-127

[4] to the people. The real estate industry and Industry Association Degree Research [D]. Chongqing University, 2014 